\title{
Circumferential Intimal Intussusception in a Case of Stanford Type-A Dissection
}

\author{
Uğur Göcen, Atakan Atalay, Yüksel Baştürk
}

Department of Cardiovascular Surgery, Çukurova University Faculty of Medicine, Adana, Turkey

Intimointimal intussusception is a rare but serious complication of aortic dissection (1). Under hemodynamic forces, this cylindrical flap of tissue can intussuscept within the false lumen causing distal obstruction (1).

A 58 year-old male patient was referred to us with chest pain that had started 3 days previously. On physical examination he had no neurological problems. Upper extremity pulses were filiform but lower extremity pulses were palpable. Echocardiography (Vivid S5, General Electric, America) showed minimal aortic regurgitation with $65 \%$ ejection fraction and minimal pericardial effusion. The patient had no malperfusion findings.

A contrast-enhanced computed tomography (CT) (Toshiba Asteion 4, Japan) scan of the patient's chest and abdomen showed no flaps in the ascending aorta (Figure 1a, Figure 1b), but a dissection flap appeared below the innominate artery (Figure 1a, Figure 1b, Figure $2 \mathrm{a}$ and Figure $2 \mathrm{~b}$ ). A nested double lumen was seen in both arcus and descenden aorta (Figure 1a, Figure 1b, Figure 2a and Figure 2b). We made a diagnosis of Stanford type-A acute dissection.

Patient and relatives' informed consent was obtained for surgery and scientific purposes. Emergency surgery was performed. After median sternotomy, hematoma was seen on the aorta (Figure 3). Antegrade cerebral perfusion was used and complete circumferential intussusception into the descending aorta was seen with the open aortic arch technique. The aortic valve had no problems and we replaced the ascending aorta successfully. The patient's postoperative course was uneventful, and he was discharged in good condition 7 days after the operation.

In all cases with antegrade invagination, circumferential dissection occurred exclusively above the coronary ostia, which coincides with wall stress distributions in the ascending aorta (2). Antegrade intussusception may occlude the arch vessels

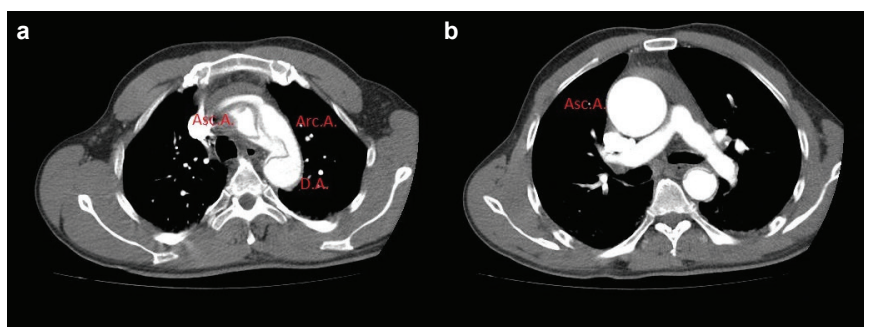

FIG. 1. a, b. Preoperative horizontal section of CT Angiography (a). Preoperative horizontal section of CT Angiography (b).

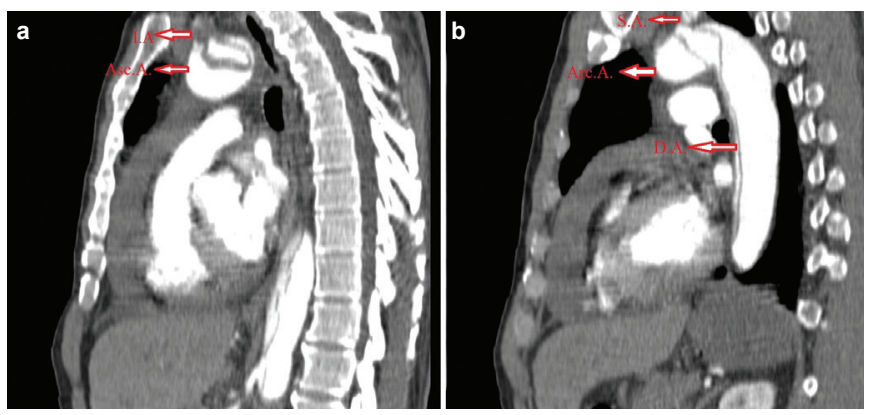

FIG. 2. a, b. Preoperative vertical section of CT Angiography. In Figure $2 a$ and Figure $2 b$, dissection of the membrane started below the innominate artery and innominate artery occlusion can be seen. Figure 2 shows arcus aorta with subclavien artery and descenden aorta.

partly or completely, causing neurologic symptoms. As many as $30 \%$ of aortic dissection cases are complicated by malperfusion of a critical organ (3). Alongside other complications, cerebral malperfusion is the most devastating (4). To react appropriately, early detection is mandatory. Interestingly, in our case, the patient had extremity pulses that were usually palpable but there was no sign of malperfusion.

An enhanced CT scan is the primary diagnostic procedure for almost all aortic dissection. However, the diagnosis of aortic dissection with intimal intussusception is difficult because

This study was presented at the $13^{\text {th }}$ Turkish Society of Cardiovascular Surgery Congress, 30 October - 2 November 2014, Antalya, Turkey.

Address for Correspondence: Dr. Uğur Göcen, Department of Cardiovascular Surgery, Çukurova University Faculty of Medicine, Adana, Turkey Phone: +905055053009 e-mail: ugurgocen@hotmail.com

Received: 17.09.2014 Accepted: 27.11.2014 • DOI: 10.5152/balkanmedj.2015.150804

Available at www.balkanmedicaljournal.org 


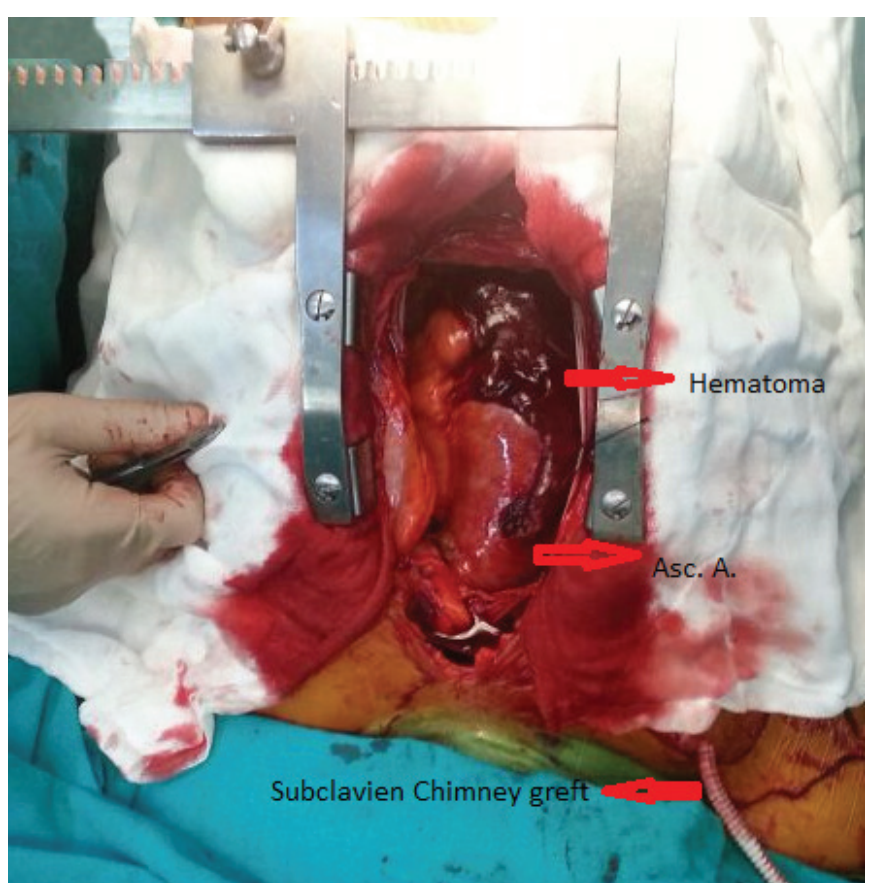

FIG. 3. Hematoma was seen over the aorta and right ventriculum. A 6 $\mathrm{mm}$ chimney graft was applied.

Asc.A.: ascenden aorta; Arc.A.: arcus aorta; D.A.: descenden aorta; I.A.: innominate artery; Arc.A.: arcus aorta; S.A.: subclavien artery

of the lack of a flap in the ascending aorta and the unusual form of invaginated flaps. Transesophageal echocardiography and magnetic resonance imaging are also sensitive diagnostic procedures for aortic dissection, but require much more time for making an accurate diagnosis. Appropriate and prompt diagnosis will permit timely and lifesaving surgical interventions for the patient.

\section{Ethics Committee Approval: N/A.}

Informed Consent: Written informed consent was obtained from the patient's wife.

Peer-review: Externally peer-reviewed.

Author contributions: Concept - U.G.; Design - U.G.; Supervision - U.G.; Resource - A.A.; Materials - Y.B.; Data Collection \&/ or Processing - U.G.; Analysis \&/or Interpretation - U.G.; Literature Search - A.A.; Writing - U.G.; Critical Reviews - A.A.

Conflict of Interest: No conflict of interest was declared by the authors.

Financial Disclosure: The authors declared that this study has received no financial support.

\section{REFERENCES}

1. Anika L. Mirick, Himanshu J. Patel, G. Michael Deeb, David M. Williams. Aortic Intussusception Complicating Diagnostic Angiography: Recognition and Management. Ann Thorac Surg 2013;95:1776-8.

2. Nathan DP, Xu C, Gorman JH III, Fairman RM, Bavaria JE, Gorman RC, et al. Pathogenesis of acute aortic dissection: a finite element stress analysis. Ann Thorac Surg 2011;91:45863.

3. Nakamura Y, Tagusari O, Ichikawa Y, Morita A. Impact of immediate aortic repair on early and midterm neurologic status in patients with acute type A aortic dissection complicated by cerebral malperfusion. Ann Thorac Surg 2011;92:336-8.

4. Williams DM, Lee DY, Hamilton BH, Marx MV, Narasimham DL, Kazanjian SN, et al. The dissected aorta: percutaneous treatment of ischemic complications -principles and results. $J$ Vasc Interv Radiol 1997;8:605-25. 